\title{
EXCAVACIONES ARQUEOLÓGICAS EN EL EXTERIOR DE LOS CONJUNTOS RUPESTRES DE LAS GOBAS (LAÑO, BURGOS)
}

\author{
POR \\ A. AZKARATE GARAI-OLAUN \\ J. L. SOLAUN BUSTINZA \\ Universidad del País Vasco
}

\section{RESUMEN}

La intervención arqueológica efectuada en Las Gobas (Laño, Condado de Treviño) se enmarca en una línea de investigación desarrollada por el Grupo de Investigación en Arqueología de la Arquitectura (UPV-EHU) que tiene por objeto el estudio de la configuración del hábitat rural en época tardoantigua y altomedieval. Los resultados alcanzados han permitido documentar una rica secuencia estratigráfica que, iniciada a caballo entre los siglos VII y VIII d.C., conserva una información histórica de primer orden. A grandes rasgos, podemos afirmar que a lo largo del siglo VII d.C. se abren ya las primeras cavidades rupestres, a las que sucederán en el tiempo algunas edificaciones exentas construidas contra ladera a los pies de las anteriores. Hacia el siglo IX, el espacio sufrirá una profunda reorganización, al abandonarse el complejo rupestre como lugar de habitación y reocuparse como área cementerial. Este espacio funerario parece mantenerse en activo hasta el siglo XI, sin que el registro arqueológico detecte ninguna otra actividad hasta el siglo xVI, momento en que el lugar volverá a ser ocupado, esta vez con un uso agrícola, dentro de un importante proceso roturador de las laderas del valle.

\section{SUMMARY}

The archaeological intervention conducted at Las Gobas (Laño, County of Treviño, Spain) is part of a line of research led by the Building Archaeology Research Group (UPV-EHU) aimed at studying the configuration of the rural habitat in Late Antiquity and the Early Middle Ages. The results achieved have allowed the documentation of a rich stratigraphic sequence that starts between the seventh and eigth centuries A.D. and preserves historical information of the first order. Broadly speaking, we can say that the seventh century A.D. saw the first cave spaces being opened up, later followed by some independent buildings set on a slope near the earlier settlements. Towards the ninth century, the space was subject to a profound reorganisation, during which the cave complex was abandoned as a dwelling place and recovered as a burial area. This funerary space seems to have remained active until the eleventh century, but archaeological investigation has not detected any other activity until the sixteenth century, when the site was reoccupied, this time for agricultural use, in a widespread process involving bringing the valley sides under the plough.

PALABRAS CLAVE: Antigüedad Tardía, Alta Edad Media, arquitectura rupestre, poblamiento, cerámica.

KEY WORDS: Late Antiquity, Early Middle Ages, cave architecture, settlement, ceramics.

\section{INTRODUCCIÓN}

Laño, pequeña pedanía perteneciente al Condado de Treviño, se emplaza en el fondo de un valle cerrado sobre sí mismo y flanqueado por grandes farallones dolomíticos que acogen a dos de los mejores conjuntos rupestres, sin duda, del norte peninsular. El de la izquierda, según entramos al valle, se conoce como Santorkaria y posee numerosas cavidades.

El conjunto de la derecha recibe el nombre de Las Gobas, topónimo parlante de origen vasco ${ }^{1}$ que responde a la existencia de 13 cavidades rupestres, dos de ellas de inequívoca funcionalidad litúrgica. Es en las inmediaciones de la más conocida de estas dos iglesias (Las Gobas 4 y 6) y justo frente a la cavidad contigua que denominamos en su día Las Gobas 7 (Azkarate 1988) donde se ha efectuado la intervención que recogemos en este trabajo.

\section{OBJETIVOS Y JUSTIFICACIÓN}

Han transcurrido bastantes años ya desde que propusiéramos algunas ideas básicas tanto sobre los orígenes de las cavidades rupestres como sobre su perduración en el tiempo. Defendíamos entonces tanto la diversidad cronológica del más del centenar de cavidades catalogadas en Álava y Condado de Treviño (Burgos) advirtiendo que «tan inexacto nos parece el suponer los fenómenos de las cuevas artificiales con vocación exclusivamente eremítica como imaginarlos, en origen, como hábitats de carácter únicamente civil» (Ibidem: 477). Concluíamos aquel estudio insistiendo en que debían evitarse «las gene-

\footnotetext{
${ }^{1}$ «La goba no es sino la romanización del vasc. goba, det. gobea, 'la cueva', variante koba, conocido y usado además de vasc. le $(i) c e$, con ese valor. No discuto, como es natural, su procedencia románica» (L. Michelena 1976, 9. 58)
} 


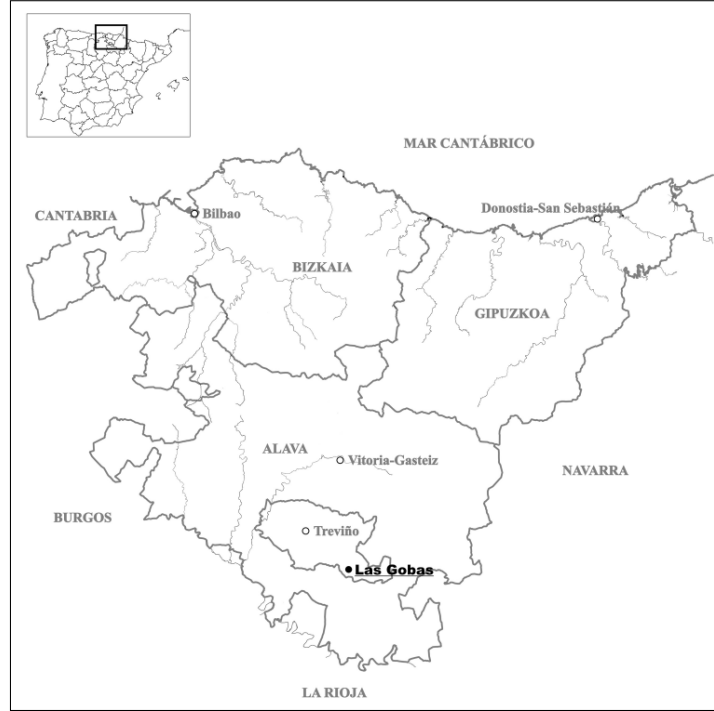

Fig. 1. Mapa de situación del yacimiento de Las Gobas.

ralizaciones abusivas referidas a la cronología de las cavidades artificiales» (Ibidem: 479-480)², máxime en un contexto historiográfico en el que los distintos modelos interpretativos sobre la evolución del poblamiento desde finales de la Antigüedad hasta bien entrada la Edad Media pugnan entre sí ofreciendo explicaciones totalizadoras y pretendidamente concluyentes. Frente a estas tentaciones, hoy tenemos que reivindicar -como entonces- «que los orígenes, cronología y funcionalidad de las cuevas artificiales han de zanjarse... mediante estudios concretos y puntuales, teniendo en cuenta las distintas ubicaciones, su contexto tanto geográfico como histórico, las diferentes tipologías, las posibles excavaciones arqueológicas... potenciando, en definitiva, los análisis monográficos, previos siempre a cualquier intento de síntesis» (Ibidem: 478). Y ello pasa necesariamente por la excavación sistemática de algunos de los lugares más significativos. Ésta es la principal de las razones de la investigación arqueológica iniciada en Las Gobas durante el verano del 2007 y de la que este texto constituye un primer avance.

\section{LA INTERVENCIÓN ARQUEOLÓGICA}

Hace ya tiempo, las inmediaciones de las dos iglesias rupestres de Las Gobas fueron objeto de excavación arqueológica por parte de José Miguel Barandia-

\footnotetext{
${ }^{2}$ Más recientemente se ha abundado también en estas mismas ideas, como puede verse en Raynaud 2001 o Quirós 2006.
}

rán, con resultados poco alentadores (Barandiarán 1968). Quizá debido a ello y quizá también a la naturaleza rocosa de las inmediaciones que no auguraba subsuelos de contenidos estratigráficamente fértiles, lo cierto es que no ha habido en cuarenta años quien se animara a continuar las excavaciones del ilustre arqueólogo vasco. Y si en esta ocasión hemos decidido hacerlo, ha sido por la necesidad de contar con contextos estratigráficos fiables en un debate que, carente de ellos, está construyendo sin embargo modelos interpretativos de cimientos no siempre sólidos.

El primer objetivo de la intervención, como puede fácilmente deducirse, no podía ser otro que el de la comprobación de los resultados ofrecidos por Barandiarán, y su posible extrapolación a las áreas contiguas. Fue por ello por lo que se decidió investigar la zona adyacente a la antigua intervención. La propia «trinchera» de los años sesenta y la existencia de un vallado que cierra y protege el área rupestre de Las Gobas 4-7 predeterminaron el emplazamiento y las dimensiones de la intervención del 2007 que quedó circunscrita, de este modo, a un rectángulo de 38 metros cuadrados que limitaba en uno de sus lados menores (Este) con el farallón rocoso, en uno de los mayores (Sur) con la excavación de los años sesenta y en los otros dos (Oeste y Norte) con el cierre metálico de protección de las cuevas que debíamos respetar por prescripción administrativa.

Los resultados alcanzados superaron las expectativas iniciales. Condicionados seguramente por la estratigrafía que publicó en su día J.M. Barandiarán ${ }^{3}$ (un mínima parte de la verdaderamente existente), no imaginábamos que el subsuelo contuviera una interesante registro arqueológico de más de dos metros de potencia. Esta última fue precisamente una de las sorpresas principales, al constatar que la topografía actual era totalmente distinta de la originaria o, dicho con otras palabras, que los constructores y primeros usuarios de las cavidades rupestres hollaron un suelo que, en algunos puntos, estaba a más de dos metros de pro-

\footnotetext{
${ }^{3}$ Nivel I: capa superficial de $30 \mathrm{~cm}$. de espesor, de tierra vegetal clara. Pequeños fragmentos vidriados, con mayoría de producciones vidriadas. Nivel II. Tierra oscura formando una capa de $20 \mathrm{~cm}$. de espesor. Contiene tiestos rojos, algunos negros finos y otros negros con desgrasante granular, a los que hay que añadir diez lascas silíceas, un fragmento de punta retocada y una hoja de cuchillo o machete de hierro. Nivel III. Debajo de las capas anteriores se documenta otra más gruesa, con $80 \mathrm{~cm}$. de espesor, de tierra amarilla que contiene algunos bloques de piedra con marcas de escoda, similares a las de las paredes de las grutas artificiales. En la base de este nivel, en tierra mezclada con abundantes gravas, se hallaron cuatro sepulturas de lajas con forma trapecial, orientadas este-oeste. La tierra inmediata superior contenía algunos tiestos rojizos, otros de barro negro fino y un trozo de hierro informe (Barandiarán 1968).
} 


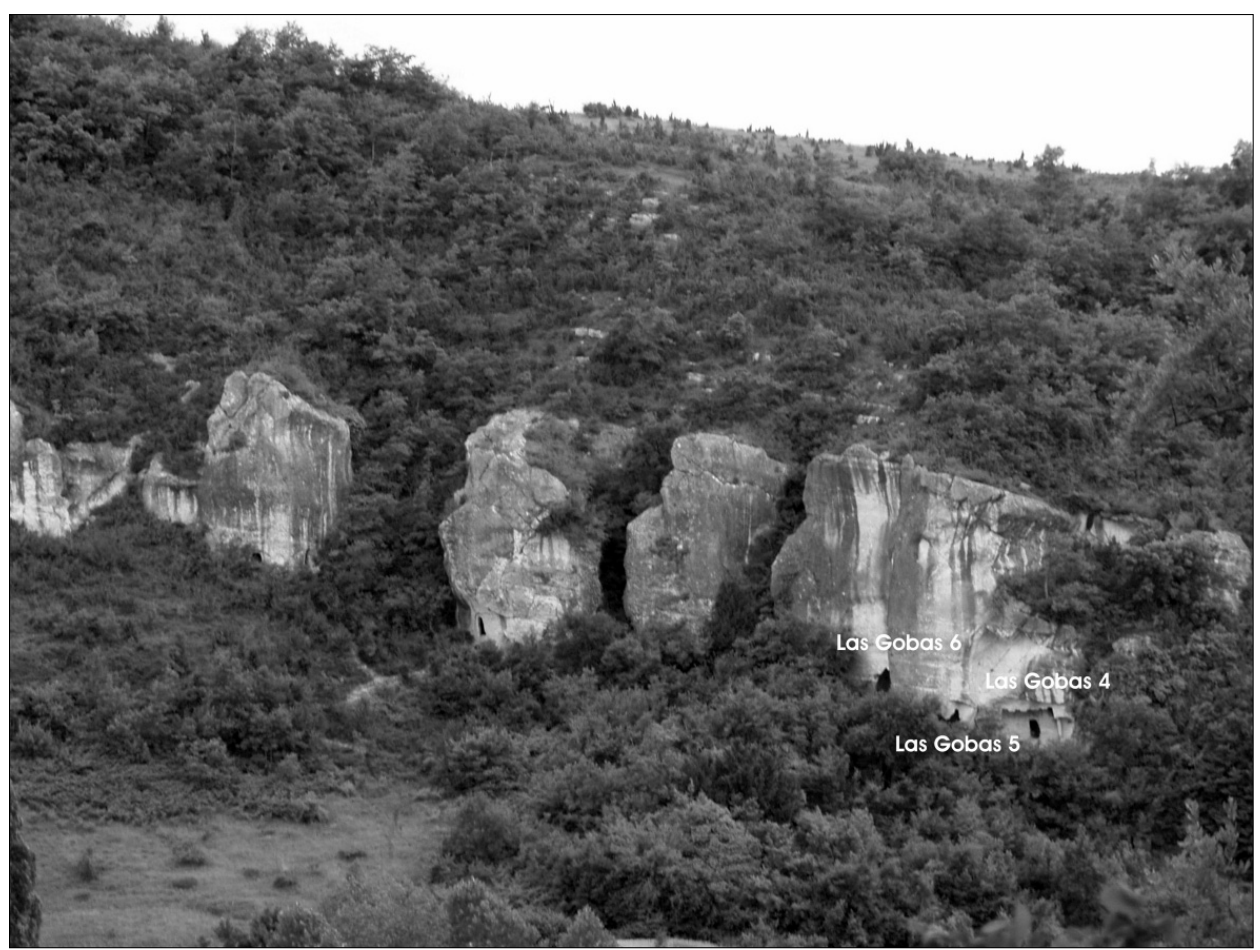

Fig. 2. Imagen del farallón rocoso de Las Gobas, con las cavidades rupestres mencionadas.

fundidad. Este suelo original arrancaba desde la base del farallón rocoso y descendía en pronunciada pendiente hacia el riachuelo que discurre por el valle.

La ocupación humana del lugar modificó prontamente la topografía primaria, originalmente en ladera. Las rocas producidas por el propio proceso de extracción y la creación de un muro de aterrazamiento, hoy en día no observable, fueron generando una plataforma que creció en potencia hasta alcanzar los dos metros largos de profundidad ya comentados.

En este paquete estratigráfico, el registro generado por la excavación arqueológica ha permitido documentar 37 unidades estratigráficas (Figs. 6 y 7) que, en un proceso de síntesis posterior ${ }^{4}$, hemos agrupa-

\footnotetext{
${ }^{4}$ El complejo armazón estratigráfico generado por una intervención arqueológica necesita de códigos específicos que permitan tanto su gestión como su interpretación y transmisión. Afortunadamente, y como resultado de diversas experiencias europeas, se han ido depurando instrumentos de síntesis que facilitan esa transición necesaria entre la analítica y la narración histórica. Nuestro Grupo de Investigación (GIAA) sigue, desde hace años, las propuestas de A. Carandini a este respecto (Historias en la tierra, Barcelona 1997), articulando sucesivamente la secuencia estratigráfica en Unidades Estratigráficas, Actividades, Grupos de Actividades, Fases y Períodos, es decir, organizando la arquitectura del conjunto de la estratificación en una serie de gradientes de contenido sintético progresivo.
}

do en 8 actividades circunscribibles a un arco cronológico que, arrancando en el siglo vII, se extiende hasta nuestros días. Veamos, en los párrafos que siguen, una síntesis de los resultados alcanzados.

Actividad 1 (Apertura de las cavidades artificiales. Primeras labores extractivas)

El inicio de la ocupación del lugar está documentado en el registro arqueológico por dos Actividades. La primera de ellas (A1) refleja el proceso de extracción que conllevó la apertura de las cavidades artificiales (restos de talla de caliza dolomítica extraídas del frente rocoso) y está constituida por dos unidades estratigráficas. La UE-20 se apoya directamente sobre la roca natural y se caracteriza por la presencia de numerosas piedras calizas de mediano y gran tamaño, contenidas en un potente paquete de arcilla y arena de color marrón oscuro. Su formación obedece, sin lugar a dudas, al proceso de excavación de las cavidades, muy posiblemente mediante la técnica de rozas y cuñas ${ }^{5}$ a juzgar por la ausencia de restos de labra en las piedras recuperadas.

\footnotetext{
${ }^{5}$ Cfr., a este respecto, F. Azkonegui, A. Castellanos, 1999, Guía práctica de la cantería, León.
} 


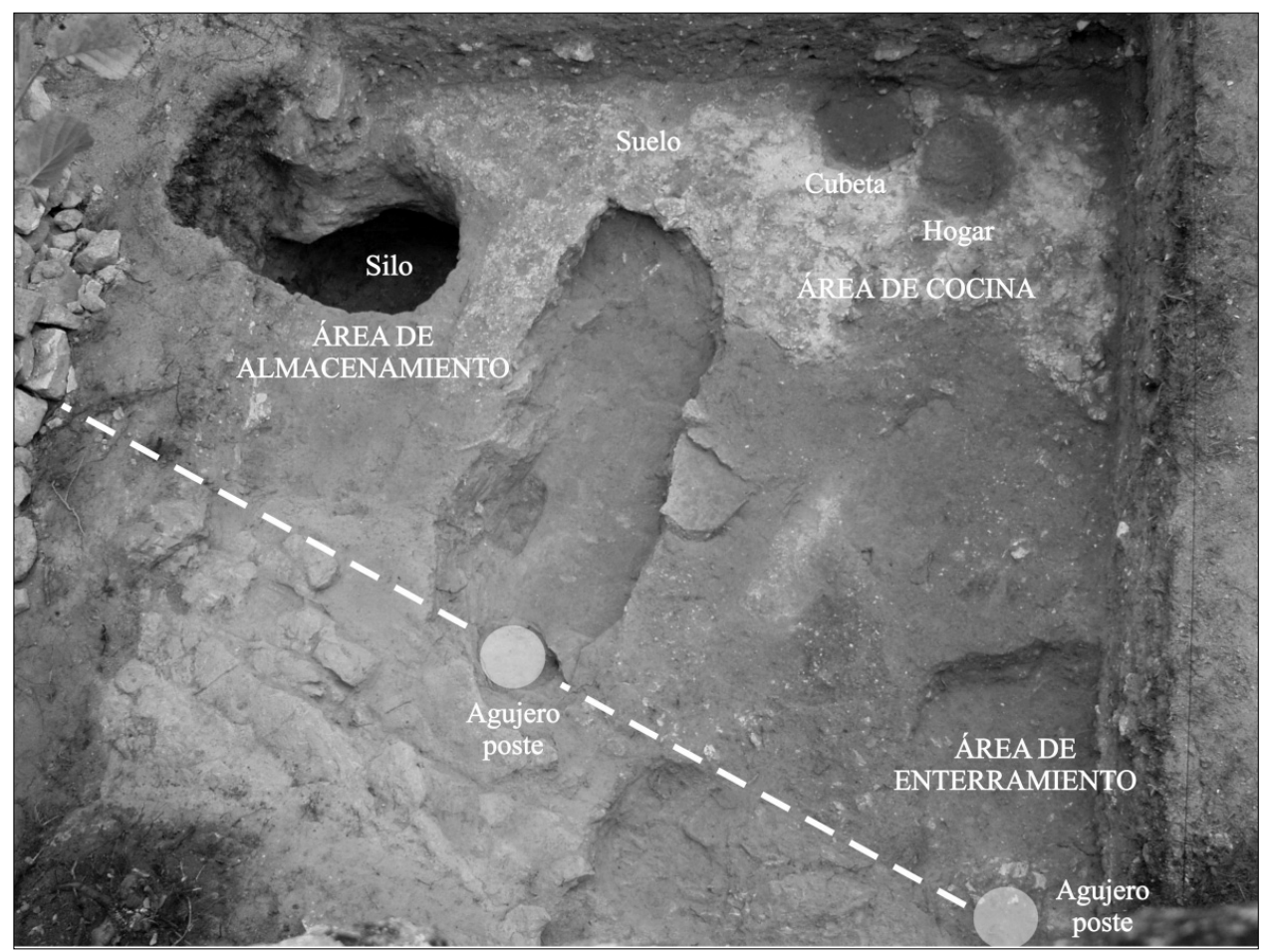

Fig. 3. Imagen cenital de las estructuras documentadas en la cabaña exenta (A2).

Los restos de talla procedentes del acabado final se reconocen en la UE-14, situada inmediatamente encima de la anterior y compuesta íntegramente por pequeñas esquirlas de piedra caliza, de un característico color blanquecino, sin intrusiones de otra naturaleza.

$\mathrm{Su}$ cronología arrancaría en algún momento de la séptima centuria. No existe, de momento, evidencia alguna que permita llevar esta fecha al siglo anterior tal y como supusimos en su momento (Azkarate 1988: 475). Los rasgos paleográficos de los graffiti que se conservan en Las Gobas-6 responden a un momento de formación de la escritura cursiva visigótica y configuran, junto con las pizarras y otras muestras paleográficas procedentes también de cuevas, un escaso aunque importante elenco de escritura peninsular del siglo vir d.C. (Velázquez 1993: 271 y 320). El material cerámico recuperado en la UE-20 y su relación estratigráfica de anterioridad respecto a la sepultura 4 que pronto comentaremos (A2) apuntan también en esta dirección.

\section{Actividad 2 (Construcción de una cabaña exenta)}

Aprovechando la explanación del lugar conseguida con los niveles de extracción descritos, se levan- tó la primera estructura no rupestre que conocemos hasta el momento y que funcionó como espacio doméstico contiguo a las cuevas artificiales. En el momento actual de la investigación resulta imposible estimar la planta y las dimensiones completas de este edificio del que sólo se han podido exhumar 16 $\mathrm{m}^{2}$. Pero, a cambio, disponemos de otros datos de interés sobre las técnicas empleadas en su construcción y su organización espacial.

Estamos, en efecto, ante una estructura levantada a nivel de suelo ${ }^{6}$ sobre gruesos postes de madera de los que, hasta el momento, conocemos únicamente dos (UE-25 y UE-36). Con una altura máxima cercana a los tres metros, la cubierta se dispuso a una sola vertiente aprovechando para el encastre de uno de sus cabios transversales (UE-30) la presencia de una gran peña en las inmediaciones. No se han recuperado restos materiales de esta cubierta, por lo que cabe imaginar el uso de paja, ramajes vegetales o cualquier otro elemento perecedero. Sus paredes debieron levantarse también con materiales efímeros, muy posiblemente tablazón de madera, puesto que no se ha detectado testimonio alguno que refleje el recurso a los entrelazados y man-

\footnotetext{
${ }^{6} \ll$ Structure de plain-pied».
} 
teados de arcilla registrados habitualmente en otras excavaciones.

A juzgar por los datos conocidos, nos encontramos ante una vivienda de espacio único que acogía, sin embargo, ambientes distintos: a) Un silo piriforme $^{7}$ emplazado en el extremo más septentrional del área excavada cumplió las funciones de almacén (UE15); b) Apenas dos metros al sur se ubicó la zona de cocina, con un hogar ovalado de arcilla decantada (UE-13) y, junto a él, una cubeta circular de $0,5 \mathrm{~m}$ de diámetro (UE-28); c) En un rebaje rectangular no muy lejano, se detectaron dos inhumaciones. Perteneciente la primera de ellas a un adulto (sepultura 5: UE-33 y UE-34), no ha podido ser excavada por encontrarse parcialmente bajo el cierre metálico que protege el acceso a las cavidades. La segunda (sepultura 4: UE 31 y UE 32) corresponde a un niño de apenas unos meses: su esqueleto se depositó en una fosa de planta ovalada ${ }^{8}$ en posición decúbito supino, con los brazos flexionados a la altura del abdomen y las piernas juntas, ligeramente ladeadas.

El cruce de resultados de los análisis radiocarbónicos efectuados en este enterramiento (770-970 AD para un $93,5 \%)^{9}$ y en el nivel que inmediatamente le cubre y que pronto comentaremos (UE-19: 660-820 AD para un $94,4 \%$ ) permiten precisar para la ejecución de la sepultura . $^{\circ} 4$ una fecha que puede ubicarse en el último tercio del siglo viII d.C. Para la construcción de la estructura que le acoge debe suponerse una cronología evidentemente anterior, a caballo entre las centurias séptima y octava.

\section{Actividad 3 (Reparación de la cabaña exenta)}

Son dos, al menos, las acciones que evidencian un replanteo o reparación de la estructura descrita: a) La primera de ellas está reflejada en el registro arqueológico por un relleno (UE-22 y UE-35) que amortiza simultáneamente tanto el rebaje rectangular (UE-23) que acogía los dos enterramientos como uno de los dos agujeros de poste (UE-36) que definía el límite occidental de la construcción que estamos analizando. La desaparición de este «pie derecho» parece obedecer a una pequeña ampliación del

\footnotetext{
$71,5 \mathrm{~m}$. de profundidad, $1,4 \mathrm{~m}$. de diámetro máximo y 1 $\mathrm{m}$. diámetro en su embocadura.

${ }^{8} 0,96 \mathrm{~m}$. de longitud, $0,50 \mathrm{~m}$. de anchura, $0,30 \mathrm{~m}$. de profundidad.

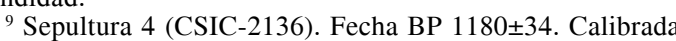
por el programa $\mathrm{OxCal} v 3.10$ proporciona las siguientes horquillas cronológicas. Al 68,2\% ó 1 ä: 770-890 AD. Al 95,4\% ó 2 ä: $770-970$ AD para un $93,5 \%$ y $720-740$ AD para un $1,9 \%$.
}

edificio por este costado. b) La segunda está testimoniada por un nuevo suelo de arena y arcilla (UE-19) que, respetando el silo y el hogar ya descritos, ocupó en su totalidad el resto de la planta del edificio.

El análisis radiocarbónico ${ }^{10}$ efectuado sobre una muestra procedente del suelo UE-19 (al que nos hemos referido recientemente) y sus propias relaciones estratigráficas de posterioridad respecto a la sepultura 4 (A2) permiten también una aproximación cronológicamente relativamente precisa que nos lleva a los años finales del siglo vIII d.C. o inicios de la centuria siguiente.

\section{Actividad 4 (Abandono del emplazamiento como lugar de hábitat)}

Esta actividad queda documentada en el registro arqueológico por la presencia, en el interior del silo, de un nivel de sedimentación compuesto por arcillas de color amarillento, muy decantadas, producto del arrastre generado por la acción del viento o agua (UE37). Destaca, asimismo, el vertido de una vaca adulta, depositada en conexión anatómica, que carecía de cabeza, cuartos traseros y parte de las manos delanteras. Tanto la naturaleza del nivel de sedimentación descrito como la reutilización del silo como basurero ocasional denuncian el abandono del emplazamiento como lugar de habitación. De hecho, el lugar acabará finalmente destruido, tal y como refleja la UE-12, compuesta por abundantes pellas de arcilla y restos carbonizados de tablazón que denuncian el arrasamiento definitivo del emplazamiento como lugar de habitación.

La analítica radiocarbónica efectuada sobre restos de madera carbonizada procedente de UE- $12^{11}$ y su propia secuencia estratigráfica (anterior a la UE5 y posterior a la UE-19) fecha esta actividad en la segunda mitad del siglo IX d.C. Estamos ante un momento de transición, de duración difícil de precisar (breve en cualquier caso), aunque de significado muy importante para la historia de Las Gobas, por cuanto constituye la interfaz entre el abandono del complejo rupestre como lugar de habitación, el traslado de los pobladores a un nuevo emplazamiento

${ }^{10}$ UE-19 (Ua-35419). Fecha BP $1270 \pm 30$. Calibrada por el programa OxCal v 3.10 proporciona las siguientes horquillas cronológicas. Al 68,2\% ó $1 \delta$ : $685-730$ AD para un $36,9 \%$ y 735-775 AD para un 31,3\%. Al 95,4\% ó 2 : $660-820$ AD para un $94,4 \%$ y $840-860$ AD para un $1 \%$.

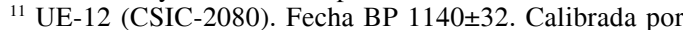
el programa $\mathrm{OxCal}$ v 3.10 proporciona las siguientes horquillas cronológicas. Al 68,2\% ó $1 \delta$ : 875-975 AD. Al 95,4\% ó $2 \delta: 780-990$ AD. 


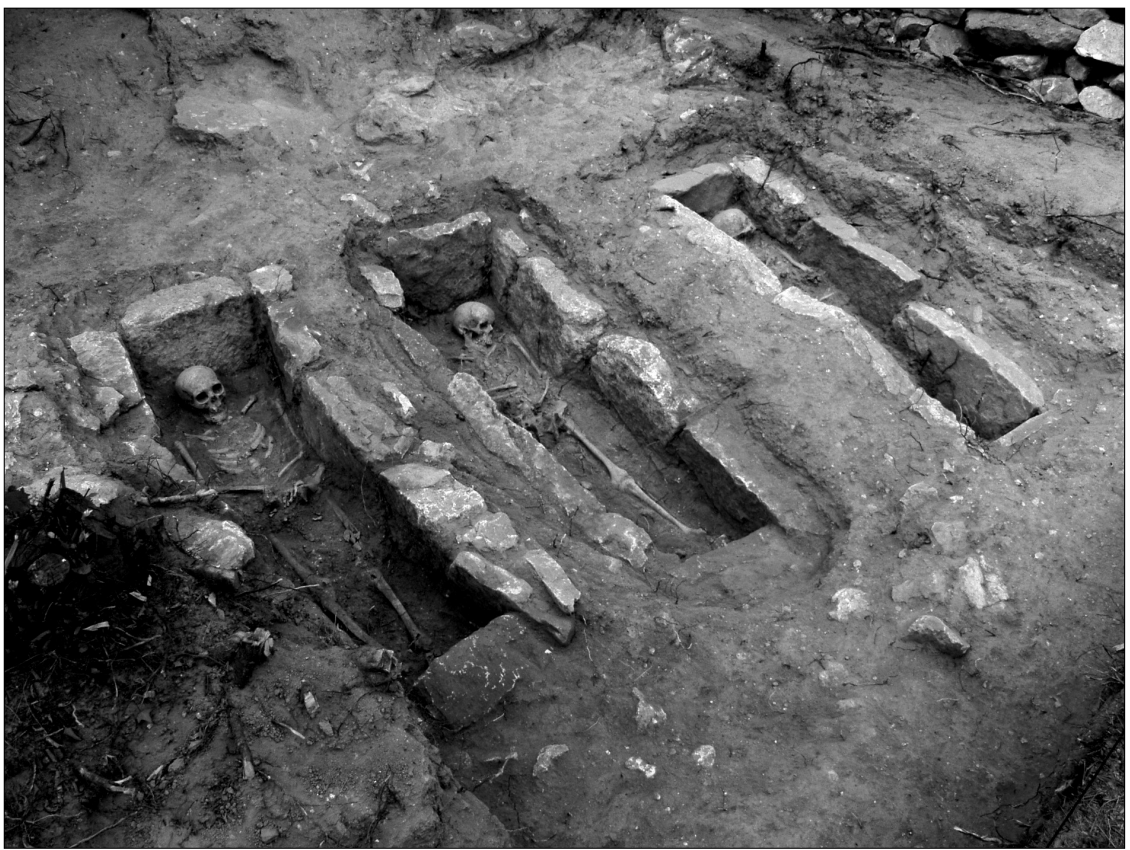

Fig. 4. Vista general de las sepulturas exhumadas en la necrópolis.

(actual localidad de Laño ${ }^{12}$ ubicada al fondo del va1le) y la «refuncionalización» de la antigua aldea rupestre como espacio funerario.

\section{Actividad 5 (Segundas labores extractivas)}

Sobre la UE-12 se registran nuevos testimonios que denuncian la reanudación de las prácticas extractivas en el lugar. Al igual que veíamos en el caso de las primeras extracciones, también en esta ocasión se detectan dos niveles: el primero de ellos (UE-16) amortizó definitivamente el silo de épocas anteriores con piedras de tamaño grande y mediano, mientras que el segundo (UE-5), conformado por arena, arcilla y numerosos restos del proceso final de talla, se extiende por buena parte de la excavación nivelando definitivamente todo este espacio.

La constatación de nuevas labores extractivas en el lugar constituye un dato de especial relevancia que no se había detectado en estudios anteriores. Su cronología debe llevarse al s. x d.C. ${ }^{13}$, posiblemente a

\footnotetext{
${ }^{12}$ Mencionada como Langu en la Reja de San Millán. Año 1025 (Ubieto 1976).

13 Análisis radiocarbónico efectuado a la UE-5 (CSIC2135 ). Fecha BP $1090 \pm 30$. Calibrada por el programa OxCal v 3.10 proporciona las siguientes horquillas cronológicas. Al $68,2 \%$ ó $1 \delta$ : $895-920$ AD para un $23,5 \%$ y $940-990$ AD para

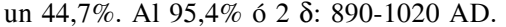

sus primeros decenios, y su constatación ayudará a despejar algunas incógnitas no resueltas nunca satisfactoriamente y a las que nos referiremos en el capítulo final.

\section{Actividad 6 (Establecimiento de un área cementerial)}

Es en la UE-5 donde se depositarán las inhumaciones pertenecientes al cementerio que transformará definitivamente un espacio que durante mucho tiempo tuvo naturaleza habitacional. En nuestra intervención hemos registrado tres sepulturas orientadas este-oeste, a las que debemos sumar otras cuatro exhumadas hace cuarenta años (Barandiarán 1968 ${ }^{14}$ ). Todas ellas poseen tipología similar: fosas rectangulares revestidas con lajas calizas dispuestas verticalmente y cubiertas por varias lajas de dimensiones similares.

- Sepultura 1 (UE-6 y UE-7). Fosa de planta rectangular $(2 \times 0,86 \times 0,35 \mathrm{mts}$.), con ocho lajas perimetrales y cinco losas a modo de cubierta, todas ellas de caliza. Su interior contenía el esqueleto de un individuo adulto, en posición decúbito supino, con el brazo derecho extendido y el izquierdo flexionado sobre el abdomen. Piernas juntas y extendidas.

${ }^{14}$ J.M. Barandiarán pensó que estos enterramientos marcaban el final de la estratigrafía. 
- Sepultura 2 (UE-8 y UE-9). Fosa de planta rectangular $(2,26 \times 0,90 \times 0,50 \mathrm{mts}$.), con once lajas perimetrales y cinco losas a modo de cubierta, también de caliza. Su interior contenía el esqueleto de un individuo adulto, en posición decúbito supino, con el brazo derecho flexionado sobre el abdomen y el izquierdo sobre el sacro. Piernas extendidas. Entre los pies se ha recuperado una placa de hierro rectangular, ligeramente arqueada, de difícil interpretación.

- Sepultura 3 (UE-10 y UE-11). Fosa de planta rectangular (2,10 x 0,92 x 0,42 mts.), con doce lajas perimetrales y cuatro losas a modo de cubierta, todas ellas de caliza. Su interior contenía el esqueleto de un individuo adulto, en posición decúbito supino, con las manos juntas sobre la pelvis y las piernas extendidas.

El periodo de uso de esta necrópolis abarca una horquilla cronológica que ocupa, al menos, todo el siglo $x$ d.C. y parte de la centuria siguiente ${ }^{15}$. En cualquier caso, quedaría pendiente tanto la delimitación precisa de su momento final como sus causas.

\section{Actividad 7 (Construcción de una terraza de cultivo)}

Nada menos que hasta el siglo XvI deberemos esperar para que se registre la siguiente actividad constructiva: un potente relleno compuesto por arcillas y arenas de grano fino (UE-4) que nivela y eleva la cota del terreno en más de $80 \mathrm{cms}$. hasta conformar una estrecha pero extensa terraza que recorre longitudinalmente la base del farallón rocoso. Bien documentado en otros lugares ${ }^{16}$, estamos ante un proceso de ocupación de ladera que se asocia a la introducción de nuevas plantas llegadas desde América, como el maíz, y a la necesidad de tierras por parte de una comunidad campesina en rápido y continuo crecimiento.

Un primer análisis del conjunto cerámico recuperado en el relleno UE-4 data esta fase en la primera

${ }^{15}$ Datación aportada por la propia secuencia estratigráfica del yacimiento y el análisis radiocarbónico efectuado a la sepultura 2 (CSIC-2137). Fecha BP 1065 \pm 42 . Calibrada por el programa $\mathrm{OxCal} \vee 3.10$ proporciona las siguientes horquillas cronológicas. Al 68,2\% ó 1 ä: $890-920$ AD para un $14,6 \%$ y 960-1020 AD para un 53,6\%. Al 95,4\% ó 2 ä: 890-1020 AD.

${ }^{16}$ Por ejemplo, en algunas comarcas de las Montañas de Burgos como Frías, donde la anexión de nuevos espacios agrícolas ganados a la montaña debía estar en pleno auge. Tanto era así que esta actividad ya se preveía en sus Ordenanzas, (Que cualquier vesino de la dicha ciudad que quisiere Romper en los montes della que en cuanto que lo comience lo venga a notificar al Regimiento) «tratando de controlar lo que debía ser ya un movimiento generalizado» (Ortega Valcárcel 1974: 161). mitad del siglo xVI, atendiendo a la ausencia de cerámica esmaltada y a la importante presencia de cerámica vidriada (44\%), similar a los porcentajes totales de cerámica común ${ }^{17}$.

\section{Actividad 8 (Testimonios contemporáneos)}

Cubriendo la UE-4 se registran dos últimas unidades estratigráficas (UE-1 y UE-2), compuestas por tierra vegetal y arenas y que a juzgar por el material que contienen (vidrios de botella, chapas metálicas actuales y plásticos), han debido formarse durante los últimos decenios del pasado siglo xx.

\section{LAS PRODUCCIÓNES CERÁMICAS MÁS ANTIGUAS}

Hace algunos años, a raíz de la reunión emeritense en torno a las cerámicas tardorromanas y altomedievales de la Península Ibérica (Caballero, Mateos, Retuerce 2003), mostrábamos nuestra extrañeza por la anómala ausencia en el País Vasco y Navarra de contextos arqueológicos de los siglos VI y VII d.C. (Azkarate, Núñez, Solaun 2003). Sorprendía, en efecto, que la mayoría de los yacimientos tardorromanos que recoge la bibliografía para estos territorios no alcanzase casi nunca horizontes cronológicos pertenecientes al siglo vi y que únicamente escapara a este desolador panorama un reducido elenco de lugares: la ciudad de Pamplona, muy posiblemente Iruña/ Veleia, el castro de Buradón, el mal conocido asentamiento de Salbatierrabide en Vitoria-Gasteiz, los complejos rupestres del mediodía alavés y norte de Burgos, algunas ocupaciones en cueva ${ }^{18}$ y en otras tantas necrópolis exhumadas en territorio alavés, vizcaíno o navarro ${ }^{19}$.

Este breve listado quedaba prácticamente reducido a cuatro o cinco asentamientos si tomábamos en consideración sólo aquellos lugares con material cerámico. Dos de ellos, Iruaxpe III (Guipúzcoa) y Aldaieta (Álava) ya fueron estudiados aprovechando la citada

\footnotetext{
${ }^{17}$ El estudio cerámico de esta unidad estratigráfica ha sido realizado por Sergio Escribano, autor de una tesis doctoral en avanzado estado de ejecución sobre la cerámica en el País Vasco durante los siglos XIV al XVII y al que agradecemos su colaboración.

${ }_{18}$ Nos referimos a la cueva guipuzcoana de Iruaxpe III en Aretxabaleta y a las alavesas de Los Goros en Hueto Arriba, los Husos II en Elvillar y muy probablemente Payo Carrascajosa en Laguardia.

19 En concreto, las de Aldaieta (Nanclares de Gamboa, Álava), San Pelayo (Alegria-Dulantzi, Álava), Finaga (Basauri, Bizkaia), Buzaga (Elorz, Navarra) y Pamplona.
} 
reunión y pudimos comprobar entonces que la cueva guipuzcoana parecía responder a un escenario «continuista», con registros que reproducían series y sistemas productivos romanos. La necrópolis alavesa, en cambio, mostraba un horizonte muy distinto, sin rastro alguno de producciones finas romanas y con presencia exclusiva de manufacturas locales asociadas a la denominada cerámica grosera ${ }^{20}$.

Con la intervención arqueológica llevada a cabo en Las Gobas, un nuevo lugar viene a sumarse a los ya mencionados, ofreciendo además un registro cerámico bien contrastado estratigráficamente y que abarca una horquilla cronológica que se extiende desde la segunda mitad del siglo vil d.C. hasta, al menos, el siglo XI d.C. Un nuevo yacimiento que ofrece varios horizontes cerámicos, aunque ahora nos fijemos únicamente en dos de ellos: uno tardoantiguo, asociado al escenario productivo visto en la necrópolis de Aldaieta y otro altomedieval, asociado a los contextos recuperados en diversas aldeas altomedievales alavesas.

\subsection{El horizonte tardoAntiguo}

Se encuentra representado por la UE-19 y la UE20 o, lo que es lo mismo, por los niveles que responden al momento de construcción de las primeras cavidades rupestres y del edificio exento que hemos descrito. Llama la atención tanto el escaso número de fragmentos recuperados como la pertenencia de todos ellos a un único tipo de cerámica grosera (Grupo $I^{*}$, rasgos ya conocidos en otros lugares y que parecen reflejar el predominio absoluto de estas producciones (con la consiguiente desaparición de las series de época romana) y el drástico descenso cuantitativo del volumen de cerámica producida y consumida. Analicemos más detenidamente estos dos últimos puntos.

1. La progresiva desaparición de las importaciones de cerámica romana y el incremento significativo de la cerámica común local durante los últimos años del siglo vi es un fenómeno bien constatado en otras zonas de la Península Ibérica (Caballero, Mateos, Retuerce 2003). Lógicamente, los ritmos cro-

\footnotetext{
${ }^{20}$ Idéntico escenario puede desprenderse del escaso material cerámico recuperado en la necrópolis tardoantigua de Finaga (García Camino 2002: 61-77) y en la de San Pelayo, donde aparecen numerosos fragmentos de cerámica grosera pertenecientes a una o varias ollas formalmente similares a las recuperadas en Aldaieta (Azkarate 1997).

* Las características concretas de éste y el resto de grupos cerámicos documentados en Las Gobas pueden consultarse en Solaun 2005.
}

nológicos de esta tendencia y el universo productivo que se genera tras la definitiva desaparición de las primeras varían dependiendo unas veces de su emplazamiento en zonas costeras o del interior peninsular, y otras de su pertenencia a un contexto urbano o rural.

En lo que respecta al Cantábrico oriental, cada vez parece más claro que es a finales del siglo vi o muy a comienzos de la centuria siguiente cuando debe situarse el cese definitivo de las importaciones de cerámica romana. No serán éstas, sin embargo, las únicas producciones en desaparecer. Otro tanto ocurrirá con la mayoría de las comunes locales que habían protagonizado la vajilla de época tardorromana ${ }^{21}$, algunas ausentes incluso para los inicios mismos del siglo vi. Solamente escapará a esta situación la cerámica grosera, una producción de larga tradición, bien documentada en contextos prerromanos y romanos de nuestro territorio, que monopolizará el ajuar cerámico del siglo vII, al menos en el ámbito rural.

Este tipo cerámico se caracteriza, a grandes rasgos, por presentar unas pastas tiernas, sin decantar y con paredes muy gruesas, con abundantes y gruesos desgrasantes que, dependiendo de su naturaleza geológica, pueden clasificarse en carbonatados (cristales de calcita y rocas calizas) y cuarcíticos. Todas ellas fueron ejecutadas a torno, si bien con un régimen de vueltas lento que, unido a las frecuentes irregularidades de sus paredes, acostumbra a generar equívocos con la cerámica no torneada.

$\mathrm{Su}$ repertorio formal y funcional se asocia siempre con la cerámica de cocina destinada al fuego, fundamentalmente ollas acompañadas puntualmente por vasos abiertos del tipo cuenco. Aunque en Las Gobas no se ha podido identificar ninguna forma específica, no debieron ser muy diferentes de las documentadas en el yacimiento de Aldaieta - con perfiles claramente paralelizables en contextos europeos continentales- o en otros contextos alaveses de cronología ligeramente posterior, como la aldea de Gasteiz, cuyas series formales reproducen modelos propios de la cerámica común romana de origen local.

2. La segunda de las cuestiones se refiere al escaso volumen de cerámica registrado hasta la fecha en Las Gobas - apenas una decena de fragmentosy la limitada presencia de la vajilla cerámica en el ajuar doméstico. La existencia de contextos prácti-

${ }^{21}$ Para conocer los principales tipos de cerámica común romana, fundamentalmente en época bajoimperial, puede consultarse el trabajo de A. Martínez Salcedo (2004), en especial el capítulo dedicado a las denominadas cerámicas no torneadas de pasta gris y de pasta rugosa/arenosa. 
camente «acerámicos» durante estos siglos constituye un fenómeno que está siendo observado cada vez con más interés y se caracterizaría por la presencia casi exclusiva de ollas y vasos destinados a la cocción de alimentos que, necesariamente, tuvieron que estar complementados por otros recipientes lígneos o metálicos (Delogu 2007).

\subsection{El HORIZONTE ALtOMEDIEVAL}

La segunda fase cerámica documentada en Las Gobas corresponde a la UE-5, un potente relleno de nivelación depositado en la primera mitad del siglo $\mathrm{x}$ sobre el que se dispuso, como vimos, una necrópolis que conocemos sólo parcialmente.

El repertorio cerámico registrado en este nivel es radicalmente distinto al descrito en el capítulo precedente, tanto en el número de fragmentos recuperados como en el de las producciones detectadas. La cerámica grosera sigue presente, pero hacen acto de presencia tres nuevas producciones - la cerámica oxidante con abundantes desgrasantes (Grupo VI), la cerámica decantada pintada en rojo (Grupo VIII) y la cerámica rugosa de pastas claras (Grupo X) en una diversificación que está reflejando sin duda una progresiva recuperación de la vajilla cerámica en el ajuar doméstico. Los porcentajes análogos de las tres nuevas producciones, con apenas un 16\%, evidencian, no obstante, que nos encontramos ante producciones aún minoritarias respecto a la cerámica grosera que, con un $50 \%$ de representatividad, sigue dominando la escena.

Desde el punto de vista de sus rasgos tecnológicos, las nuevas manufacturas - elaboradas a torno y horneadas a temperaturas siempre superiores a los $800^{\circ} \mathrm{C}$ - suponen una notable mejora respecto a la cerámica grosera, y otro tanto cabría decir respecto al nuevo repertorio formal. Aunque en Las Gobas sólo ha podido identificarse un tipo de jarro o cántaro del Grupo VI, en otros contextos de los siglos IX y x (Gasteiz, Rivabellosa, etc.) se ha documentado un amplio abanico de series cerámicas (ollas, platos, cuencos, jarros, orzas, cántaros y tinajas) que evidencian un ajuar mucho más diversificado y especializado funcionalmente. Veamos, brevemente, las distintas producciones:

- Producción local (Grupo I). Sigue siendo la fuente de aprovisionamiento principal, con un $50 \%$ de la cerámica consumida y se asocia con sistemas productivos marcadamente domésticos, de productividad esporádica o estacional y que desarrollaría formas básicas de intercambio.
- Producción regional (Grupo VI). La cerámica oxidante con abundantes desgrasantes puede identificarse con una producción del entorno próximo, muy posiblemente de la cuenca de inundación de un río con aportes relacionados con diapiros (quizás del río Bayas o del río Berrón, ambos en territorio alavés). A diferencia de la anterior, se asocia con la producción en talleres rurales más o menos especializados y estables, con una capacidad de producción e ingresos importantes que se comercializaría a nivel local $\mathrm{y}$ regional.

- Producción suprarregional (Grupos VIII y X). $\mathrm{Su}$ identificación con manufacturas extrarregionales se ha realizado atendiendo básicamente a los análisis arqueométricos de laboratorio. La «cerámica rugosa de pastas claras» muestra arcillas relacionadas con la alteración de materiales graníticos provenientes de la cuenca alta del Duero o la cabecera del Ebro, mientras que las características técnicas, decorativas y porcentuales de la «cerámica decantada pintada en rojo» invitan a pensar en un origen también exógeno, quizás de la zona de Cantabria, Palencia o Burgos (Solaun 2005: 307ss).

El panorama productivo que se nos desvela es, como se ve, bastante más complejo que el descrito anteriormente, aunque estemos todavía lejos de los niveles de utilización documentados en contextos posteriores, principalmente a partir del siglo XI, cuando la cerámica se convierte ya en el principal componente del ajuar doméstico. Pero, hasta entonces, y aunque no podamos hablar ya de contextos «acerámicos», su presencia en el registro arqueológico sigue siendo todavía escasa y tuvo que seguir siendo complementado por otras vajillas de carácter lígneo o metálico.

La información conservada en el registro arqueológico, sin embargo, refleja la capacidad de los habitantes del lugar para acceder a determinados productos cerámicos ajenos a su entorno inmediato y la aparición de talleres especializados. El Grupo VI denuncia la presencia de alfares en el propio territorio alavés, en alguna de las aldeas que van consolidándose a partir ya del siglo viII y que, desde su constitución, cuentan con una estructura económica compleja y diversificada de base agropecuaria, complementado con diversas actividades de carácter artesanal $^{22}$ (Quirós 2006; Azkarate 2007).

${ }^{22}$ En cualquier caso, la implantación de talleres cerámicos en territorio alavés no parece aún muy desarrollada, bien porque aún no ha cristalizado la red aldeana, bien porque sólo unas pocas aldeas cuentan con este tipo de instalaciones artesanales. A juzgar por la escasa representación del Grupo VI, todo parece indicar que esta cerámica no se elaboró en el 


\section{Producciones cerámicas}

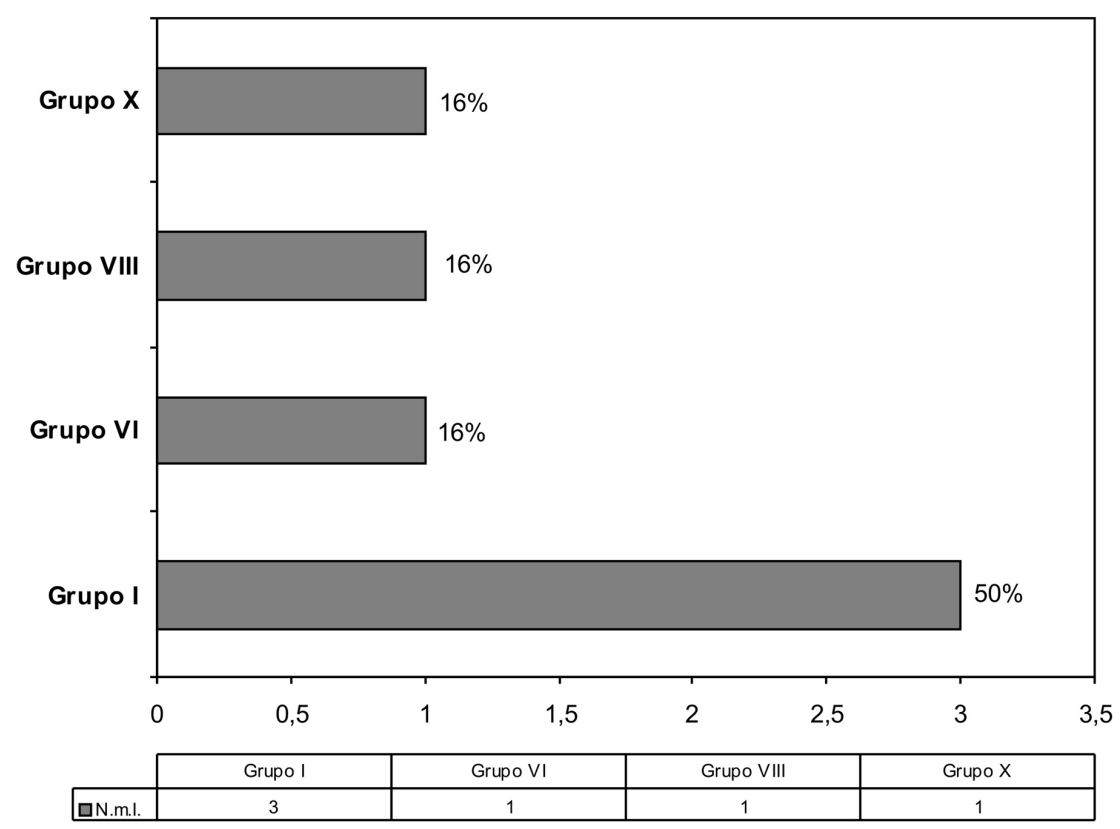

Formas cerámicas
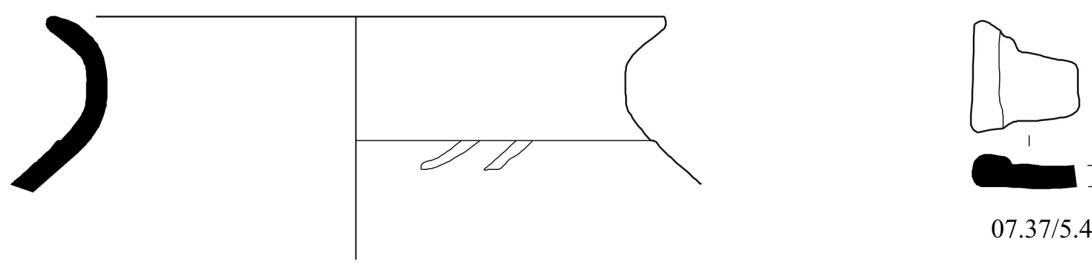

$07.37 / 5.4$

$07.37 / 5.1$

Grupo I. Cerámica grosera

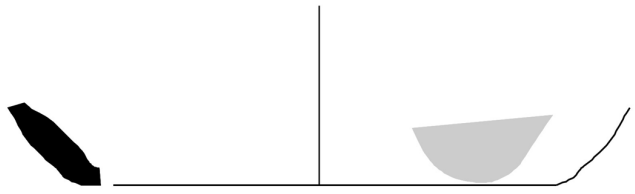

$07.37 / 5.17$

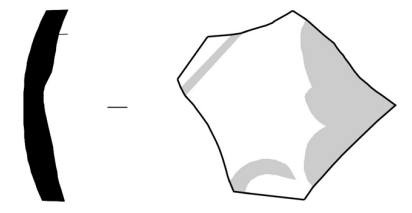

$07.37 / 5.18$

Pigmento rojo

Grupo VIII. Cerámica decantada pintada en rojo

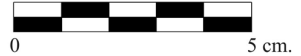

Fig. 5. Arriba, histograma con la cuantificación de los grupos cerámicos registrados en la UE-5. Abajo, formas cerámicas asociadas a los Grupos I v VIII. 
Mayores redes de distribución necesitan el Grupo VIII y el Grupo X para llegar a este destino, si bien es probable que en algún momento compartieran circuitos de comercialización con el Grupo VI. No cabe duda que, desde el punto de vista de la comercialización y distribución de las cerámicas, también se observa un panorama bastante más complejo del considerado tradicionalmente, donde los intercambios apenas superarían la escala local o, a lo sumo, la regional. La importación de cerámica desde ámbitos suprarregionales refleja la existencia de un comercio a media y larga distancia, posiblemente débil aún, así como la participación activa en este comercio de asentamientos «marginales» como las cavidades rupestres ${ }^{23}$.

\section{ALGUNAS REFLEXIONES FINALES SOBRE LA CRONOLOGÍA Y FUNCIONALIDAD DE LAS CUEVAS ARTIFICIALES DE LAÑO}

Tras la intervención arqueológica que hemos sintetizado someramente, vamos a plantear algunas cuestiones de interés para la comprensión de las cuevas artificiales, cuestiones que fueron esbozadas en su momento (Azkarate, 1988) y que parecen recibir confirmación veinte años después. Hoy, como entonces, queremos huir de las generalizaciones abusivas, recordando que las ideas que se expresan a continuación deben relacionarse únicamente con los conjuntos de Las Gobas.

En efecto, no resulta fácil —ni aconsejable — ser concluyente sobre la naturaleza de las cuevas artificiales. Han sido muchas las interpretaciones propuestas: para algunos, el arranque y funcionalidad principal de ciertas cavidades tuvo mucho que ver con la inestabilidad de los siglos bajoimperiales (González Blanco et alii 1979; González Blanco 1993; Espinosa 2006); otros han preferido interpretarlas como verdaderos loca sacra, oratoria transformados en puntos de auctoritas moral y objeto de deseo de jerarquía episcopales y aristocracias laicas en sus estrategias de control (Castellanos 1998); ha habido también quien, en ciertos casos y para determinadas regiones, las ha querido relacionar con lugares de habitación y espacios de culto de pequeñas comunidades mixtas de inspiración monástica (López Quiroga 2004); más recientemente se ha sugerido que

propio asentamiento que estamos analizando, sino en su entorno regional, lo que presupone también la existencia de mecanismos de distribución a media distancia.

${ }^{23}$ La constatación de este hecho evidencia, por si sólo, la escasa marginalidad de estas ocupaciones. quizá respondan sencillamente a la ocupación de espacios marginales por poblaciones campesinas de época tardoantigua (Quirós 2006); o que, dependiendo de las especificidades regionales, no sean en definitiva sino consecuencia de una pluralidad de factores (Brogiolo, Chavarria 2007). En fin, todo es posible. La historiografía continuará generando argumentos ad novitatem (con el riesgo de acabar cayendo en un debate ad nauseam) mientras no nos preocupemos por abordar, de manera sistemática, estudios monográficos capaces de construir registros arqueológicos serios y fiables. Por nuestra parte, la campaña de 2007 en Las Gobas ha constituido un primer paso en esta dirección, con resultados creemos que interesantes y que pueden sintetizarse en los puntos siguientes:

1. El arranque de las cuevas artificiales de Las Gobas parece situarse en el siglo vII d. C., retrasando un poco la cronología que aventurábamos hace años (Azkarate 1988).

2. Nunca hemos descartado, genéricamente, que ciertas cavidades tuvieran en origen un carácter eremítico y fueran precedentes de centros monacales nacidos a comienzos del siglo IX en sus inmediacio$n^{24}{ }^{24}$. La cercanía de algunas de estas cuevas a reconocidos cenobios altomedievales apuntan en esta dirección. Pero no parece ser el caso de los complejos de Las Gobas y de Santorkaria. Interpretados en su momento como lauras eremíticas (Ibidem), quizá fuera más correcto ponerlos en relación con asentamientos rurales de carácter aldeano nacidos en fechas anteriores a las que tradicionalmente veníamos suponiendo. Los testimonios exhumados en esta primera campaña arqueológica parecen apuntar en esta dirección.

3. En su día (Azkarate 1988) defendimos el abandono de las cuevas de Las Gobas y Santorkaria como lugares de habitación y su reaprovechamiento posterior con carácter cementerial. Con argumentos que ahora no vienen al caso (Ibidem 331, 473-480) -y que, de cualquier manera, hoy corregiríamos sustancialmente- propusimos entonces el siglo IX d.C. como horizonte cronológico en el que pudo efectuarse este abandono. Los nuevos datos procedentes de la excavación efectuada confirman aquella primera aproximación cronológica. Parece, en efecto, que los habitantes de Las Gobas abandonaron el lugar para trasladarse —en algún momento de la segunda mitad del siglo Ix o primeros años del siglo $\mathrm{x}$ - a un nuevo emplazamiento (a una nueva aldea) que hoy

\footnotetext{
${ }^{24}$ Sobre el carácter eremítico de ciertas cavidades rupestres véase también Brogiolo, Gheraldi, Ibsen 2002.
} 
conocemos como Laño y que, a mediados del siglo XI, recibía el nombre de Langu, tal y como recoge la Reja de San Millán, 1025 (Ubieto 1976).

4. Finalmente, la constatación en el registro estratigráfico de importantes depósitos de carácter extractivo para esas mismas fechas $\left(1^{\mathrm{a}} \mathrm{mitad}\right.$ del siglo $\mathrm{x}$ ), nos pone sobre la pista de otro problema no resuelto satisfactoriamente hasta el momento. Nos referimos a la iglesia de Las Gobas 4, poseedora de algunos rasgos constructivos - como sus fajones o su altar en bloque adosado- siempre percibidos como extraños al periodo tardoantiguo (Caballero 1989) y que encontrarían explicación, sin embargo, en un horizonte cronológico más próximo al cambio de milenio.

\section{BIBLIOGRAFÍA}

AzKarate, A., 1988, Arqueología cristiana de la Antigüedad Tardía en Álava, Guipúzcoa y Vizcaya, Vitoria-Gasteiz.

- 1999, Necrópolis tardoantigua de Aldaieta (Nanclares de Gamboa, Álava), Volumen I. Memoria de la excavación e inventario de los hallazgos, Memorias de yacimientos alaveses, $n^{\circ} 6$, VitoriaGasteiz.

- 2007, «Sobre las huellas iniciales de un asentamiento altomedieval en el País Vasco», en «Homenaje a Ignacio Barandiarán Maestu», Veleia 24-25, 2007, pp. 1283-1299.

Azkarate, A.; NúÑEz, J.; Solaun, J. L., 2003, «Materiales y contextos cerámicos de los siglos VI al x en el País Vasco», Anejos del Archivo Español de Arqueología XXVIII, pp. 321-370.

BARANDIARÁN, J.M., 1968, «Excavaciones arqueológicas en grutas artificiales de Álava», Estudios de Arqueología Alavesa 3, pp. 111-119.

Brogiolo, G.P., 2007, «Dall'Archeologia dell'Architettura all'Archeologia della complessità», Pyrenae 38, vol. 1, pp. 7-38.

Brogiolo, G.P.; Gheraldi, V.; Ibsen, M., 2002, «Insediamenti rupestri nell'Alto Garda bresciano», Archeologia Medievale XXIX, pp. 75-96.

Brogiolo, G.P.; Chavarría, A. (A cura di), 2007, Archeologia e società tra tardo antico e alto medioevo, Documenti di Archeologia 44, Mantova.

Caballero, L.; Mateos, P.; Retuerce, M. (eds.), 2003, Cerámicas tardorromanas y altomedievales en la Península Ibérica. Ruptura y continuidad, Anejos del Archivo Español de Arqueología, XXVIII, Madrid.
Caballero, L., 1989, «Un "modelo" de estudio de nuestra arqueología paleocristiana», Archivo Español de Arqueología 62, pp. 352-354.

Castellanos, S., 1998, Poder social, aristocracias y hombre santo en la Hispania Visigoda. La Vita Aemiliani de Braulio de Zaragoza, Logroño.

Delogu, P., 2007, «Conclusioni», en Brogiolo, G.P.; Chavarría, A. (a cura di), Archeologia e società tra tardo antico e alto medioevo, Documenti di Archeologia 44, pp. 401-404.

Espinosa, U., 2006, «Civitates y territoria en el Ebro Medio: continuidad y cambio durante la Antigüedad Tardía», en U. Espinosa y S. Castellanos (eds.), Comunidades locales y dinámicas de poder en el norte de la Península Ibérica durante la Antigüedad Tardía, Logroño, pp. 41-100.

García Camino, I., 2002, Arqueología y poblamiento en Bizkaia, siglos VI-XII. La configuración de la sociedad feudal, Bilbao.

González Blanco, A.; Espinosa Ruiz, U.; Sénz GonZÁLEZ, J. M. ${ }^{\text {a }, ~ 1979, ~ « L a ~ p o b l a c i o ́ n ~ d e ~ L a ~ R i o j a ~ e n ~}$ los siglos oscuros», Berceo 96, pp. 81-111.

GonZÁlez Blanco, A., 1993, «La investigación sobre las cuevas», Antigüedad y Cristianismo X, pp. 15-40.

LÓPEZ Quiroga, J., 2004, El final de la antigüedad en la Gallaecia: la transformación de las estructuras de poblamiento entre Miño y Duero (siglo $V$ al X), Santiago de Compostela.

Nartínez SAlcedo, A., 2004, La cerámica común de época romana en el País Vasco, Bilbao.

Martín Viso, I., 2006, «La configuración de un espacio de frontera: propuestas sobre la Vasconia tardoantigua», en U. Espinosa y S. Castellanos (eds.), Comunidades locales y dinámicas de poder en el norte de la Península Ibérica durante la Antigüedad Tardía, Logroño, pp. 101-140.

Quirós CAstillo, J.A., 2006, «La génesis del paisaje medieval en Álava: la formación de la red aldeana», Arqueología y Territorio Medieval 13.1, pp. 49-83.

Quirós Castillo, J.A.; Vigil-Escalera, A., 2006, «Networks of peasant villages between Toledo and Velegia Alabense, northwestern Spain (V-Xth centuries)», Archeologia Medievale XXXIII, pp. 79-128.

Raynaud, Cl., 2001, «L'occupation des grottes en Gaule méditerranéenne à la fin de l'Antiquité», Les campagnes de la Gaule à la fin de l'Antiquité, Colloque international AGER IV, Antibes, pp. 449-471.

Solaun Bustinza, J.L., 2005, La cerámica medieval en el País vasco (ss. VIII-XIII). Sistematización, 
evolución y distribución de la producción, Vitoria-Gasteiz.

Ubieto Arteta, A., 1976, Cartulario de San Millán de la Cogolla (759-1076), Valencia.

VelázQuez, I., 1993, «Las inscripciones latinas de la cueva de La Camareta», La cueva de La Camareta, Antigüedad y Cristianismo X, pp. 267-321.

Recibido el 22-04-08.

Aceptado el 15-09-08.

\section{ANEXO}

\begin{tabular}{|c|c|c|c|c|}
\hline UE & DEFINICIÓN & ANTERIOR A & POSTERIOR A & MATERLALES \\
\hline 1 & Nive1 superficial & & 2 & \\
\hline 2 & Nivel de relleno bajo 1 & 1 & 3,4 & Cerámica, vidrio y fauna \\
\hline 3 & Nive1 de talla & 2,4 & & Cerámica y fauna \\
\hline 4 & Nivelación de la terraza & 2 & $3,5,6,8,10$ & Cerámica, teja y fauna \\
\hline 5 & $\begin{array}{l}\text { Nive 1 de relleno para } \\
\text { necrópolis }\end{array}$ & $4,7,9,11$ & $12,13,14,16$ & $\begin{array}{l}\text { Cerámica, cristal, metaly } \\
\text { fauna }\end{array}$ \\
\hline 6 & Relleno del enterramiento 1 & 4 & 7 & Cerámica y fauna \\
\hline 7 & Fosa del enterramiento 1 & 6 & 5 & \\
\hline 8 & Relleno del enterramiento 2 & 4 & 9 & Cerámica, metal y fauna \\
\hline 9 & Fosa del enterramiento 2 & 8 & $5,24,26$ & \\
\hline 10 & Relleno del enterramiento 3 & 4 & 11 & Cerámica y fauna \\
\hline 11 & Fosa del enterramiento 3 & 10 & 5 & \\
\hline 12 & Nive1 de amortización edificio & 5 & 17 & Cerámica y fauna \\
\hline 13 & Hogar & 5,19 & 14 & \\
\hline 14 & Nive 1 de talla blanco & 5,13 & 20 & \\
\hline 15 & Silo & 16,37 & 14 & \\
\hline 16 & Segundo relleno del silo & 5 & 15,37 & \\
\hline 17 & Suelo de cal & 18 & 19 & \\
\hline 18 & Suelo & 12 & 17,21 & \\
\hline 19 & Suelo & 12,17 & $13,14,22$ & $\begin{array}{c}\text { Cerámica, pasta vítrea } \\
\text { metal y fauna }\end{array}$ \\
\hline 20 & Nivel de talla & 14,23 & & Cerámica e industria lítica \\
\hline 21 & Rebaje en el natural & 18 & & \\
\hline 22 & Relleno de UE 23 & 19 & $23,31,33,35$ & \\
\hline 23 & Rebaje para enterramientos & $22,32,34,36$ & 20 & \\
\hline 24 & Relleno de UE 25 & 9 & 25 & \\
\hline 25 & Agujero de poste & 24 & & \\
\hline 26 & Relleno de UE 27 & 9 & 27 & \\
\hline 27 & Corte en el natural & 26 & & \\
\hline 28 & Cubeta & 29 & 14 & \\
\hline 29 & Relleno de UE 28 & 19 & 28 & \\
\hline 30 & Mechinal en el peñasco & & & \\
\hline 31 & Relleno del enterramiento 4 & 22 & 32 & \\
\hline 32 & Fosa del enterramiento 4 & 31 & 23 & \\
\hline 33 & Relleno del enterramiento 5 & 22 & 34 & \\
\hline 34 & Fosa del enterramiento 5 & 33 & 23 & \\
\hline 35 & Relleno de UE 36 & 22 & 36 & \\
\hline 36 & Agujero de poste & 35 & 23 & \\
\hline 37 & Primer relleno del silo & 16 & 15 & $\begin{array}{l}\text { Bóvido en conexión } \\
\text { anatómica }\end{array}$ \\
\hline
\end{tabular}

Fig. 6. Tabla de unidades estratigráficas documentadas durante el proceso de excavación. 


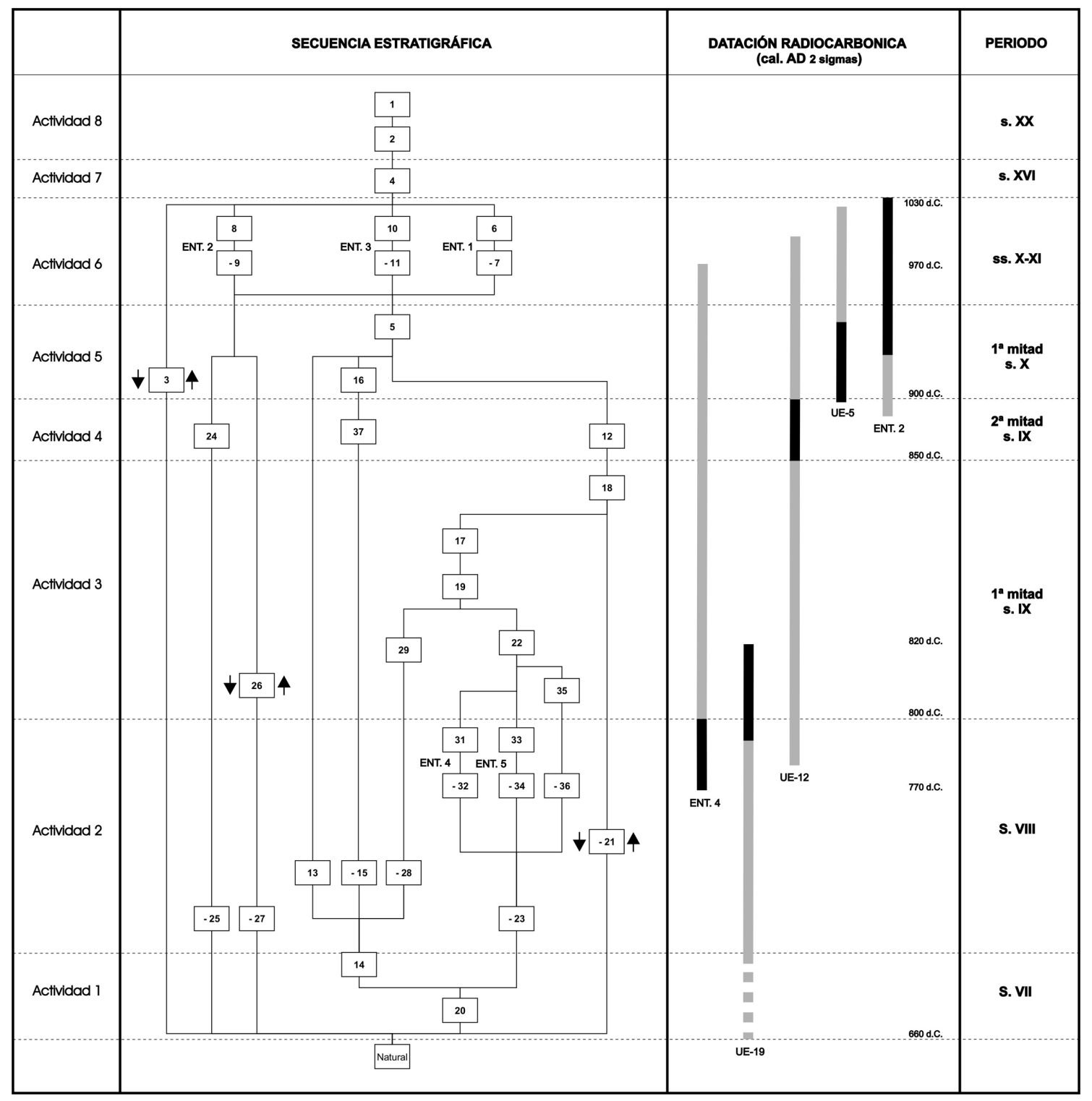

Fig. 7. Matrix de unidades estratigráficas complementada con los datos cronológicos aportados por las analíticas radiocarbónicas. 

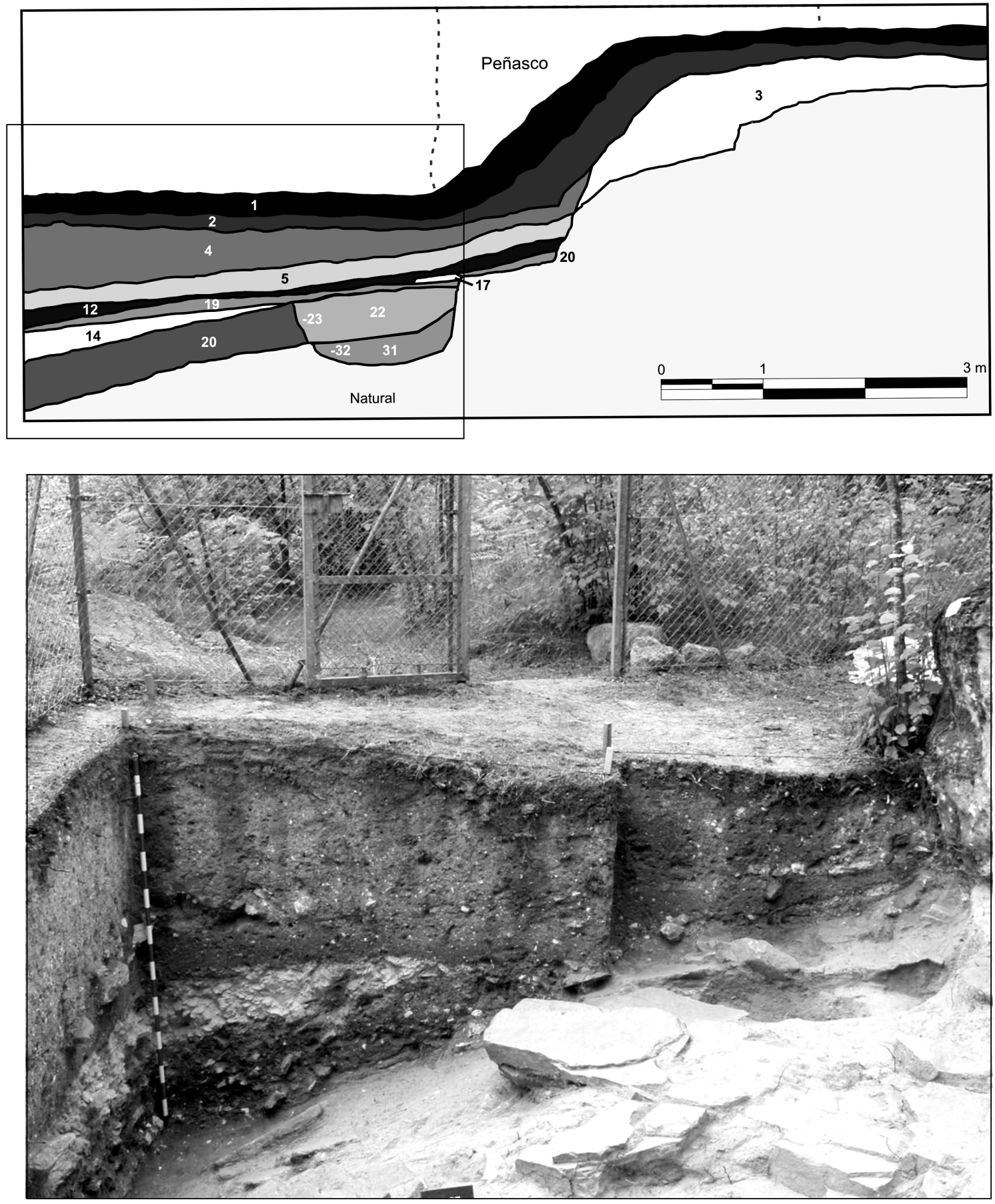

Fig. 8. Sección este-oeste perteneciente al extremo meridional del espacio excavado. 


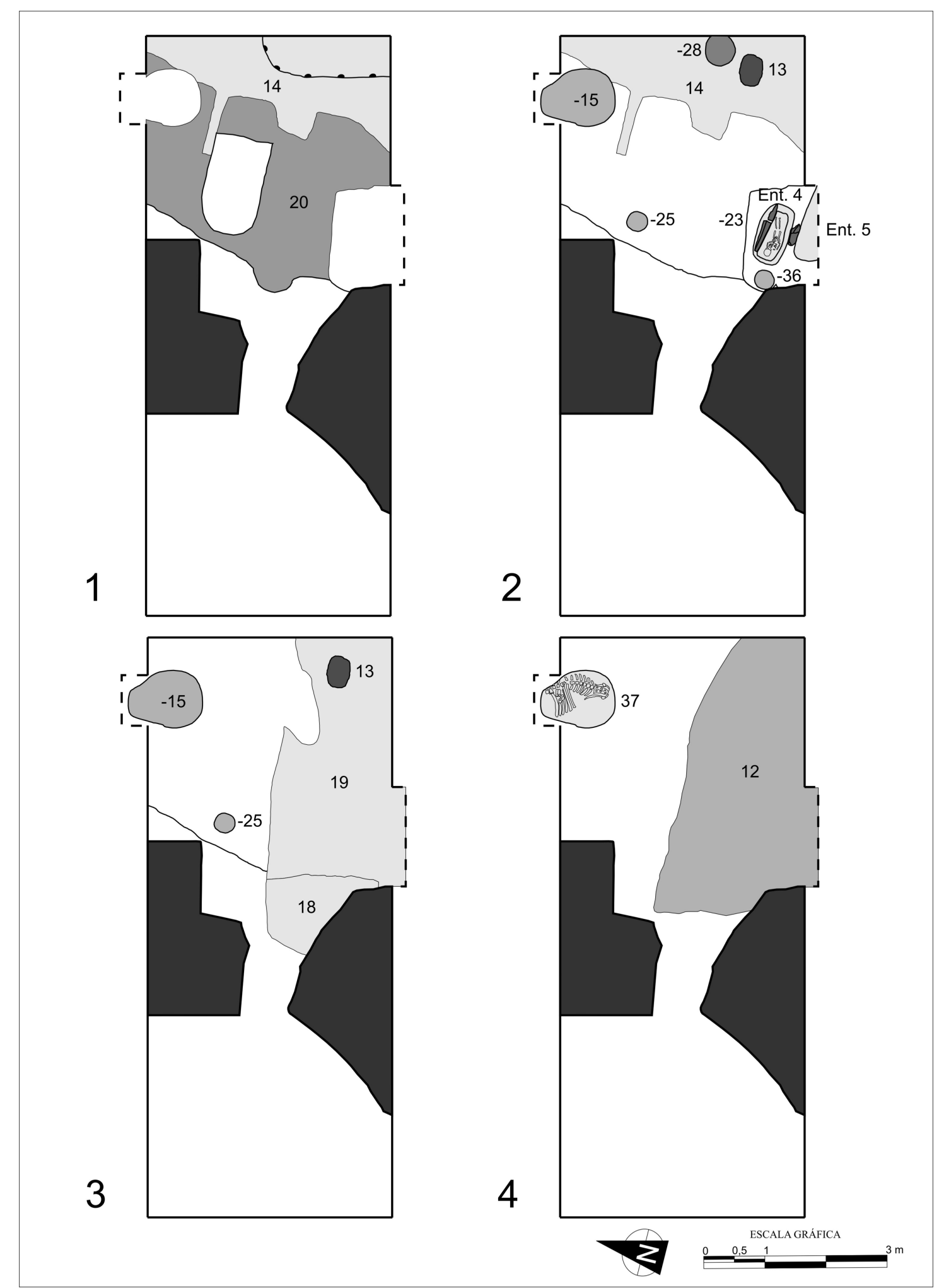

Fig. 9. Planta con las unidades estratigráficas que integran las actividades 1, 2, 3 y 4. 


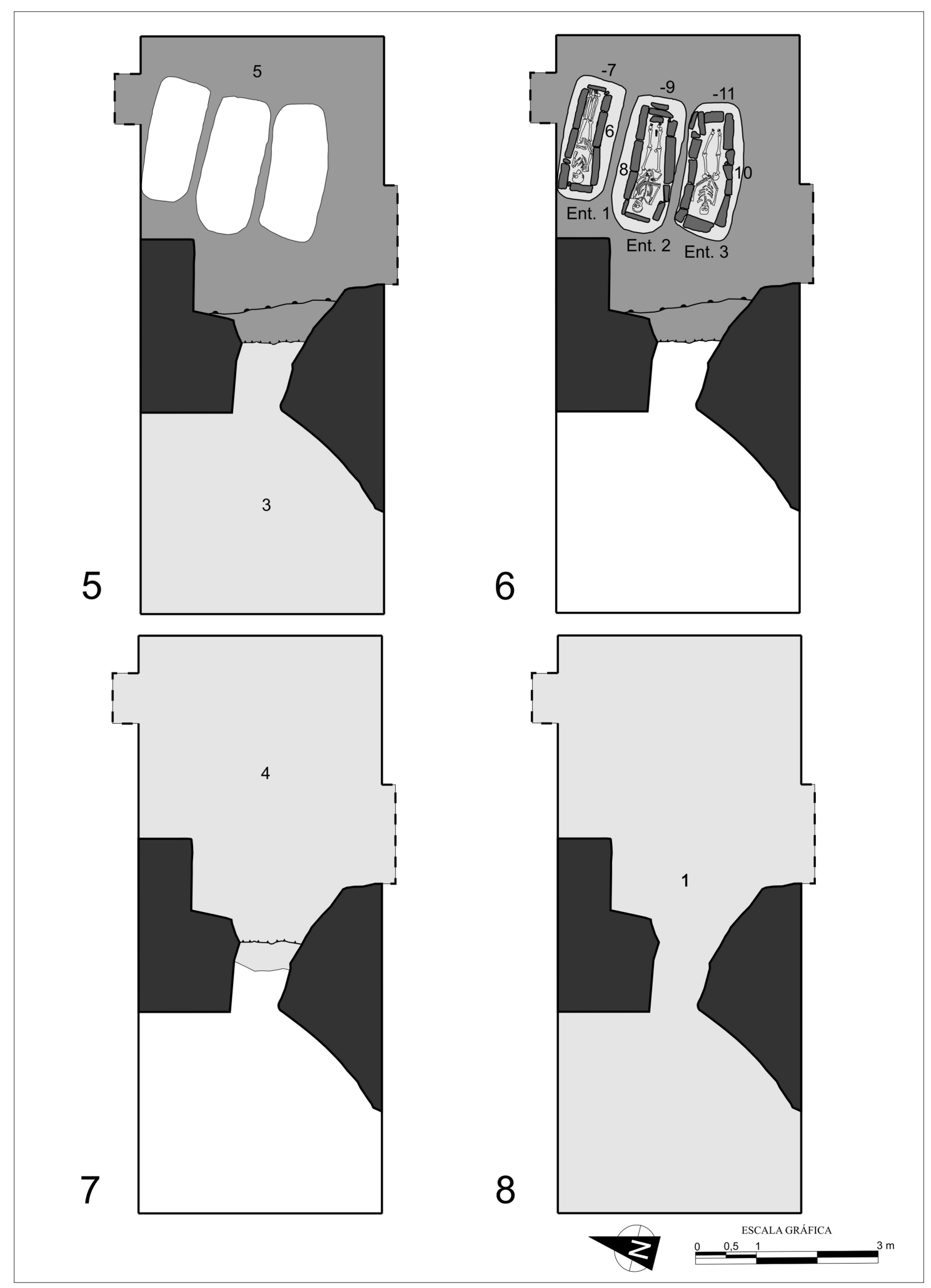

Fig. 10. Planta con las unidades estratigráficas que integran las actividades $5,6,7$ y 8 . 